\title{
ANALISIS TIMBAL DALAM LINDI (Leachate) SECARA KOAGULASI MENGGUNAKAN POLIALUMINIUM KLORIDA
}

\author{
Astrianty Unwakoly ${ }^{1}$, Nikmans Hattu' ${ }^{2}$, Y. H. Dulanlebit ${ }^{1}$ \\ ${ }^{1}$ Departement of Chemistry-FKIP, Pattimura University Ambon \\ ${ }^{2}$ Departement of Chemistry-MIPA, Pattimura University Ambon
}

Diterima 05 Oktober 2018/Disetujui 18 November 2018

\begin{abstract}
Leachate is a liquid arising from the decomposition of waste that has decayed due to the flow of external water into the landfill. Leachate can be toxic. generally, leachate contains several high inorganic metals, including lead. Lead is one type of heavy metal that has a high toxicity. This study aims to determine the initial concentration of lead $(\mathrm{Pb})$ in leachate and the percent efficiency of polyaluminium chloride (PAC) coagulant in reducing lead levels in IPST Toisapu, Ambon City. Lead content was analyzed by coagulation using an atomic absorption spechtrophotometer (AAS). Coagulation is a chemichal process used to remove particles that can cause environmental pollution. The coagulant used is a polyaluminium chloride coagulant. The results of the analysis showed that the initial lead concentration at IPST Toisapu was $2.7670 \mathrm{mg} / \mathrm{L}$ and the percentage of PAC coagulant efficiency was 500, 600, 700, 800 and $1000 \mathrm{mg} / \mathrm{L}$ respectively $61,59 \% ; 69,92 \% ; 73,55 \% ; 77,17 \%$ and $84,79 \%$. The results showed that PAC coagulant was effective in reducing lead levels in leachate.
\end{abstract}

Keywords: Leachate, Coagulation, Coagulant Polyaluminium Chloride (PAC), Lead (Pb).

\begin{abstract}
ABSTRAK
Lindi merupakan cairan yang timbul dari hasil dekomposisi sampah yang telah membusuk akibat masuknya air eksternal ke dalam timbunan sampah. Lindi dapat bersifat toksik. Secara umum, lindi mengandung beberapa logam anorganik yang tinggi, diantaranya timbal. Timbal adalah salah satu jenis logam berat yang memiliki tingkat toksisitas yang tinggi. Penelitian ini bertujuan untuk mengetahui konsentrasi awal timbal (Pb) dalam lindi dan persen efisiensi koagulan polialuminium klorida (PAC) dalam menurunkan kadar timbal pada IPST Toisapu kota Ambon. Kandungan logam timbal dianalisis secara koagulasi menggunakan Spektrofotometer serapan atom (SSA). Metode koagulasi adalah proses kimia yang digunakan untuk menghilangkan partikel yang dapat menyebabkan pencemaran lingkungan. Koagulan yang digunakan adalah koagulan polialuminium klorida. Hasil analisis menunjukan konsentrasi awal timbal di IPST Toisapu sebesar 2,7670 mg/L dan persentase efisiensi koagulan PAC 500, 600, 700, 800 dan 1000 mg/L masing-masing 61,59\%; 69,92\%; 73,55\%; 77,17\% dan $84,79 \%$. Hasil penelitian menunjukan bahwa koagulan PAC efektif dalam menurunkan kadar timbal dalam lindi.
\end{abstract}

Kata kunci: Lindi (Leachate), Koagulasi, Koagulan Polialuminium Klorida (PAC), Logam Timbal (Pb).

\section{PENDAHULUAN}

Lindi merupakan cairan yang timbul dari hasil dekomposisi sampah yang telah membusuk akibat masuknya air eksternal ke dalam timbunan sampah. Lindi dapat merembes ke dalam tanah, atau mengalir dipermukaan tanah dan bermuara pada aliran air sungai (Gandhimathi dkk., 2013).

Hasil penelitian Kusmayadi (1986) tentang analisis susunan kimia lindi sampah segar dan sampah yang telah membusuk dan bercampur dengan tanah yang bersal dari TPA, menunjukan bahwa lindi mengandung beberapa unsur yang berkadar tinggi (lebih dari $10 \mathrm{mg} / \mathrm{L}$ ) seperti Nitrogen (N), Kalsium (Ca), Magnesium (Mg), Besi (Fe) dan Kalium (K). Menurut Tchobanoglous (1993) lindi 
mengandung unsur-unsur yang dibutuhkan tanaman, diantaranya organik nitrogen $(10-600 \mathrm{mg} / \mathrm{L})$, amonium nitrogen (10-800 mg/L), nitrat (5-40 mg/L), fosfor total (1-70 mg/L), total besi (50-600 mg/L).

Hasil pengukuran komposisi unsur menggunakan XRF menunjukkan bahwa pada sampel lindi terdapat unsur logam berat, unsur logam berat tersebut adalah titanium (Ti), vanadium $(\mathrm{V})$, khrom $(\mathrm{Cr})$, mangan $(\mathrm{Mn})$, besi $(\mathrm{Fe})$, kobalt $(\mathrm{Co})$, seng $(\mathrm{Zn})$, rodium $(\mathrm{Rh})$, neodinium $(\mathrm{Nd})$, eopium (Eu), iterbium (Yb), indium (In) dan sirkon (Zr) (Sari dan Afdal, 2017). Pengukuran kandungan logam berat pada TPA Jelekong mendapatkan unsur logam berat yang terkandung pada lindi yaitu unsur $\mathrm{Mn}, \mathrm{Fe}$, $\mathrm{Co}, \mathrm{Ni}, \mathrm{Cd}, \mathrm{Pb}, \mathrm{Cu}$, dan $\mathrm{Zn}$ (Huliselan dan Bijaksana, 2006).

Secara umum, lindi mengandung senyawa organik dan beberapa logam anorganik yang tinggi. Logam anorganik yang memiliki tingkat toksisitas yang tinggi antara lain adalah $\mathrm{Hg}, \mathrm{Cd}, \mathrm{Cu}, \mathrm{Ag}, \mathrm{Ni}$, $\mathrm{Pb}, \mathrm{As}, \mathrm{Cr}, \mathrm{Sn}, \mathrm{Zn}$ dan Mn. Lindi dapat bersifat toksik karena adanya zat pengotor dalam timbunan yang mungkin berasal dari buangan limbah industri, debu, lumpur hasil pengolahan limbah-limbah rumah tangga yang berbahaya, atau dari dekomposisi yang normal terjadi pada sampah dan dapat menyebabkan pencemaran lingkungan (Susanawati dkk., 2011). Jika dilihat dari hasil penelitian sebelumnya tentang kandungan logam anorganik dalam lindi, maka dapat dinyatakan bahwa di dalam lindi terdapat logam berat termasuk timbal.

Timbal merupakan salah satu jenis logam berat yang memiliki tingkat toksisitas yang tinggi. Logam ini dapat berasal dari limbah industri, rumah tangga, baterai tidak terpakai maupun hasil penambangan (Davis dan Cornwel, 1991). Timbal yang tercemar dalam lindi dapat dihasilkan dari berbagai buangan manusia seperti baterai bekas, aki bekas, plastik, pembungkus rokok, sisa kemasan pestisida, dan cat (Widyasari dkk., 2013). Pencemaran timbal dapat terjadi di udara, air maupun tanah. Pencemaran timbal di udara berasal dari gas buangan kendaraan bermotor yang dihasilkan dari pembakaran yang kurang sempurna pada mesin kendaraan bermotor. Pencemaran timbal di perairan dan tanah melalui penggunaan bahan kimia yang langsung mengenai tanah dan pengendapan limbah buangan (Gusnita, 2012).

Timbal masuk ke dalam tubuh manusia melalui dua cara yaitu lewat udara dan bahan makanan yang mengandung timbal. Timbal yang masuk ke dalam tubuh manusia dapat mempengaruhi sistem saraf, merusak otak dan ginjal bahkan menyebabkan kematian baik pada orang dewasa maupun anak-anak yang disebabkan karena kadar timbal yang tinggi (Department of Health and Human Services, 2007).

Kadar timbal yang tinggi akan bersifat toksik maka timbal harus ditangani sebelum mencemari lingkungan dan masuk ke dalam tubuh manusia. Sejumlah teknik telah dilakukan untuk menurunkan beberapa kandungan logam berat dalam lindi, diantaranya ialah koagulasi. Metode koagulasi merupakan cara yang dapat diterapkan dalam upaya mengurangi bahaya dari pencemaran logam berat (Aminzadeh dkk., 2007). Metode koagulasi merupakan proses adsorpsi oleh koagulan terhadap partikel yang menyebabkan netralisasi partikel. Ada beberapa jenis koagulan di antaranya adalah polialuminium klorida (PAC), sodium aluminat, aluminium sulfat, ferri sulfat, feri klorida dan ferro sulfat yang digunakan untuk mengendapkan logam berat.

Lindi memiliki tingkat kekeruhan yang tinggi maka kaogulan yang efektif adalah koagulan PAC. Koagulan PAC mempunyai kelebihan, yaitu PAC lebih cepat membentuk flok dibandingkan koagulan lain, PAC bekerja pada $\mathrm{pH}$ yang luas, dan tidak menjadi keruh jika pemakaiannya berlebihan (Bao dkk., 2005).

Hasil penelitian Syahru dkk (2013), tentang perbandingan efektivitas koagulan PAC, tepung biji kelor dan tawas menunjukkan bahwa tepung biji kelor mampu menurunkan turbiditas sebesar $95,39 \%$, menurunkan kadar warna sebesar $75,07 \%$, dan menyebabkan kenaikan TSS sebesar 70,27 $\%$. Polialuminium klorida mampu menurunkan turbiditas sebesar $99,95 \%$, menurunkan kadar warna sebesar $91,73 \%$, dan kenaikan TSS sebesar $55,52 \%$. sementara itu, tawas mampu menurunkan turbuditas sebesar $93,44 \%$, menurunkan kadar warna sebesar $87,55 \%$, dan kenaikan TSS sebesar $93,36 \%$. Hasil perbandingan efektivitas antara polyalumunium chloride (PAC), tepung biji kelor dan tawas menunjukkan penggunaan PAC lebih efektif digunakan pada proses koagulasi. 
Polialuminium klorida telah digunakan secara luas sebagai flokulan untuk air, limbah industri, dan beberapa aplikasi koagulasi-flokulasi lainnya. Hal ini disebabkan karena kadar korida yang optimal dalam fase cair bermuatan negatif akan lebih cepat bereaksi. Berdasarkan latar belakang di atas, maka dalam penelitian ini telah dilakukan analisis kemampuan PAC terhadap logam $\mathrm{Pb}$ dalam lindi menggunakan metode koagulasi. Hasil koagulasi di analisis menggunakan Spektrofotometer Serapan Atom (SSA). Sampel lindi pada penelitian ini diambil dari Instalasi Pengolahan Sampah Terpadu Toisapu di Kota Ambon. adalah:

Berdasarkan latar belakang di atas, maka yang akan menjadi permasalahan pada penelitian ini

1. Berapa konsentrasi $\mathrm{Pb}$ di dalam lindi pada Instalasi Pengolahan Sampah Terpadu dusun Toisapu kota Ambon?

2. Berapa persen efisiensi koagulan PAC menurunkan konsentrasi Pb dalam lindi di IPST Dusun Toisapu Kota Ambon?

\section{METODE PENELITIAN}

\section{A. Tempat dan Waktu Penelitian}

Penelitian ini dilakukan di Laboratorium Balai Teknik Kesehatan Lingkungan dan Pengendalian Penyakit (BTKL-PP) kelas II Ambon, pada bulan Januari - Maret 2018.

\section{B. Alat dan Bahan}

1. Alat

Peralatan yang digunakan dalam penelitian ini adalah sebagai berikut:

- Peralatan gelas merk pyrex

- pH meter

- Spektrofotometer Serapan Atom (SSA) Shimadzu AA7000

- Neraca analitik ohaus

- Pengaduk magnet

- Pompa vakum

2. Bahan

Bahan yang digunakan dalam penelitian ini adalah sebagai berikut:

- Poli Aluminium Klorida (PAC)

- Larutan induk Pb 1000 ppm

- Kertas saring Whatman

- $\mathrm{NaOH} 13 \%$

- $\mathrm{H}_{2} \mathrm{SO}_{4} \%$

- Aquades

- Sampel lindi

\section{Prosedur kerja}

1. Penyiapan larutan standar

a. Pembuatan larutan standar 100 ppm dari larutan induk $\mathrm{Pb} 1000$ ppm

Sebanyak $10 \mathrm{~mL}$ larutan induk $1000 \mathrm{ppm}$ diambil dan dimasukkan ke dalam labu takar $100 \mathrm{~mL}$ dan diencerkan dengan aquades sampai tanda batas.

b. Pembuatan larutan standar $10 \mathrm{ppm}$ Sebanyak $10 \mathrm{~mL}$ larutan induk $\mathrm{Pb}$ 
100 ppm diambil dan dimasukkan ke dalam labu takar $100 \mathrm{~mL}$ dan diencerkan dengan aquades sampai tanda batas.

c. Pembuatan deret larutan standar Hasil dari pembuatan larutan standar

$10 \mathrm{ppm}$, kemudian dibuat deret larutan standar 0,2 ppm; 0,4 ppm; 0,6 ppm; 0,8 ppm; 1,0 ppm; 2,0 ppm; 5,0 ppm; dan 10,0 ppm dengan mengambil larutan standar $10 \mathrm{ppm}$ masing-masing sebanyak $2 \mathrm{~mL} ; 4 \mathrm{~mL} ; 6 \mathrm{~mL} ; 8 \mathrm{~mL} ; 10 \mathrm{~mL} ; 20 \mathrm{~mL} 50 \mathrm{~mL}$; dan $100 \mathrm{~mL}$ kemudian dimasukkan kedalam labu takar $100 \mathrm{~mL}$ dan diencerkan sampai tanda batas. Sederetan larutan standar $\mathrm{Pb}$ yang dibuat kemudian di ukur absorbansinya menggunakan Spektrofotometer Serapan Atom (SSA).

\section{Penentuan konsentrasi awal $\mathrm{Pb}$ dalam air lindi}

Sebanyak $50 \mathrm{~mL}$ sampel lindi diukur absorbansinya menggunakan instumen SSA untuk penentuan konsentrasi awal $\mathrm{Pb}$.

\section{Pembuatan Larutan PAC 500, 600,700, 800 dan $1000 \mathrm{mg} / \mathrm{L}$}

Ditimbang $500 \mathrm{mg}, 600 \mathrm{mg}, 700 \mathrm{mg}, 800 \mathrm{mg}$ dan $1000 \mathrm{mg}$ padatan PAC dan dimasukkan ke dalam masing-masing labu ukur $1000 \mathrm{~mL}$ dan ditambahkan aquades hingga tanda batas.

\section{Penentuan pH Lindi Optimum}

Untuk menentukan $\mathrm{pH}$ optimum akan dibuat variasi $\mathrm{pH}$ 6, 7, 8 dan 9, karena proses koagulasi menggunakan PAC dengan rentang pH 6 - 9. Sebanyak $250 \mathrm{~mL}$ sampel lindi dimasukkan ke dalam 4 buah erlenmeyer, ditambahkan larutan $\mathrm{H}_{2} \mathrm{SO}_{4} \%$ tetes per tetes sambil diukur $\mathrm{pH}$ menggunakan $\mathrm{pH}$ meter sampai $\mathrm{pH} 6$ dan 7, sedangkan untuk variasi $\mathrm{pH} 8$ dan 9 ditambahkan $\mathrm{NaOH} 13 \%$, kemudian tambahkan larutan PAC $500 \mathrm{mg} / \mathrm{L}$ sebanyak $1 \mathrm{~mL}$ dan dianalisis menggunakan SSA. $\mathrm{pH}$ optimum yang diperoleh pada tahap ini akan digunakan untuk proses selanjutnya.

\section{Proses Koagulasi}

Koagulasi dilakukan dengan menggunakan pengaduk magnet. Masukkan masing-masing 250 $\mathrm{mL}$ limbah lindi ke dalam lima buah erlenmeyer, kemudian tambahkan larutan $\mathrm{H}_{2} \mathrm{SO}_{4} \%$ sampai $\mathrm{pH}$ optimum. Selanjutnya campuran ditambahkan koagulan PAC dengan variasi PAC (500mg/L; 600 $\mathrm{mg} / \mathrm{L}, 700 \mathrm{mg} / \mathrm{L}, 800 \mathrm{mg} / \mathrm{L}$ dan $1000 \mathrm{mg} / \mathrm{L}$ ) sebanyak $1 \mathrm{~mL}$ dan diaduk selama 10 menit. Pengadukan dihentikan dan didiamkan selama 30 menit. Filtrat yang diperoleh dianalisis secara Spektrofotometer Serapan Atom.

\section{Teknik Analisis Data}

Data yang diperoleh berupa absorbansi larutan lindi dan PAC setelah dikoagulasi pada variasi konsentrasi dan dibuat grafik untuk memperoleh suatu garis lurus antara absorbansi dan konsentrasi dengan menggunakan persamaan regresi linier yaitu: $y=a x+b$, dimana $x$ adalah konsentrasi dan $y$ adalah absorbansi, maka konsentrasi $\mathrm{Pb}$ setelah adsorpsi dihitung menggunakan persamaan:

$$
x=\frac{y-b}{a}
$$

Data konsentrasi $\mathrm{Pb}$ selanjutnya dipakai untuk menentukan efisiensi adsorpsi. Persentase efisiensi adsorpsi $\mathrm{Pb}$ menggunakan koagulan PAC dihitung menggunakan persamaan:

$$
(\%)=\frac{C o-C e}{a} \times 100 \%
$$

Dimana:

Co: Konsentrasi awal (mg/L) 
Ce: Konsentrasi Akhir (mg/L)

(Widiastuti dkk, 2011)

\section{HASIL PENELITIAN}

\section{A. Penentuan Konsentrasi Timbal dalam Lindi (leachate)}

Pertambahan jumlah penduduk setiap tahunnya dapat menyebabkan peningkatan produksi sampah. Semakin besar volume sampah akan membuat peningkatan jumlah bahan organik dan anorganik yang ada di dalam lindi. Semua sampah yang dihasilkan di kota Ambon akan di tampung di Instalasi Pengolahan Sampah Terpadu (IPST) di Dusun Toisapu yang merupakan tempat pembuangan akhir sampah di kota Ambon.

Sampah organik yang terdekomposisi akan menghasilkan lindi (leachate). Lindi merupakan hasil dari dekomposisi sampah dan cairan yang masuk ke tempat pembuangan. Lindi berpotensi menyebabkan perncemaran lingkungan. Hal ini di sebabkan karena lindi mengandung bahan organik dan anorganik termasuk timbal. Timbal merupakan salah satu logam berat yang bersifat toksik. Timbal yang terkandung dalam lindi dapat dihasilkan dari berbagai buangan seperti baterai bekas, aki bekas, plastic pembungkus makanan, pembungkus rokok, sisa kemasan pestisida, dan cat. Berdasarkan hasil analisis timbal dalam lindi menggunakan spektrofotometer serapan atom menunjukkan adanya kandungan timbal dalam lindi IPST Toisapu sebesar 2,67 mg/L. Dengan demikian dapat disimpulkan bahwa timbal dalam lindi di IPST Dusun Toisapu telah melebihi ambang batas yang ditetapkan dalam Peraturan Menteri Lingkungan Hidup RI No. 5 tahun 2014 yakni baku mutu timbal dalam air limbah adalah $0,3 \mathrm{mg} / \mathrm{L}$.

\section{B. Pembuatan Kurva Standar}

Pembuatan kurva standar dilakukan dengan mengukur absorbansi larutan standar timbal $(\mathrm{Pb})$ pada konsentrasi 0,$2 ; 0,4 ; 0,6 ; 0,8 ; 1,0 ; 2,0 ; 5,0$ dan 10,0 ppm menggunakan spektrofotometer serapan atom pada panjang gelombang $282,97 \mathrm{~nm}$. Berdasarkan data hasil pengukuran absorbansi larutan standar timbal $(\mathrm{Pb})$ pada berbagai konsentrasi selanjutnya dibuat kurva standar hubungan absorbansi terhadap konsentrasi larutan standar timbal $(\mathrm{Pb})$, dan diperoleh persamaan regresi $\mathrm{y}=$ $0,0233 x+0,0001$ dengan $R^{2}=0,9991$ (Gambar 1).

Nilai koefisien korelasi $\left(R^{2}\right)$ yang mendekati 1 menunjukkan adanya hubungan yang linear antara absorbansi dan konsentrasi larutan standar timbal $(\mathrm{Pb})$. Persamaan regresi yang diperoleh digunakan untuk menentukan konsentrasi timbal $(\mathrm{Pb})$ setelah di koagulasi menggunakan polialuminium klorida (PAC).

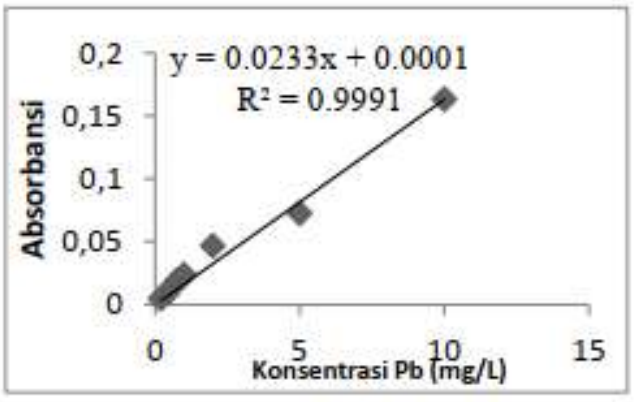

Gambar 1. Kurva Standar Timbal (Pb)

\section{Proses Koagulasi}




\section{Penentuan pH Optimum Lindi}

$\mathrm{pH}$ memiliki pengaruh yang besar terhadap pengendapan logam karena Setiap koagulan memiliki kondisi optimumnya masing-masing dalam mengendapkan polutan dalam limbah. Penentuan $\mathrm{pH}$ optimum bertujuan untuk mengetahui pada $\mathrm{pH}$ berapa terjadi adsorpsi optimum logam $\mathrm{Pb}$ oleh PAC. Penentuan $\mathrm{pH}$ optimum ini dilakukan dengan membuat variasi $\mathrm{pH}$ sampel lindi yakni 6, 7, 8 dan 9. penambahan larutan $\mathrm{NaOH}$ dan larutan $\mathrm{H}_{2} \mathrm{SO}_{4}$ digunakan untuk membuat larutan pada kondisi yang diinginkan. $\mathrm{pH}$ divariasikan sebesar 6-9 disebabkan karena koagulan PAC dapat bekerja efektif pada $\mathrm{pH}$ 6-9. Kemudian ditambahkan koagulan PAC dan dilakukan pengadukan.

Penurunan kandungan logam $\mathrm{Pb}$ dalam lindi terjadi karena terbentuknya endapan $\mathrm{Pb}(\mathrm{OH})_{2}$ dan $\mathrm{Pb}\left(\mathrm{SO}_{4}\right)_{2}$. Adanya logam yang mengendap mengakibatkan konsentrasi logam yang terlarut semakin kecil. Adapun reaksi yang terjadi dengan penambahan $\mathrm{NaOH}$ dan $\mathrm{H}_{2} \mathrm{SO}_{4}$ adalah sebagai berikut:

$$
\begin{aligned}
& \mathrm{Pb}^{2+}+\mathrm{NaOH} \longrightarrow \mathrm{Pb}(\mathrm{OH})_{2}+\mathrm{Na}^{+} \\
& \mathrm{Pb}^{2+} \mathrm{H}_{2} \mathrm{SO}_{4} \longrightarrow \mathrm{Pb}\left(\mathrm{SO}_{4}\right)_{2}+\mathrm{H}^{+}
\end{aligned}
$$

Setelah penambahan koagulan, langkah selanjutnya diikuti pengadukan agar larutan homogen serta terbentuk flok. Penyaringan dilakukan kemudian untuk menghilangkan flok. Semakin cepatnya pengadukan, semakin banyak tumbukan yang terjadi antar partikel.

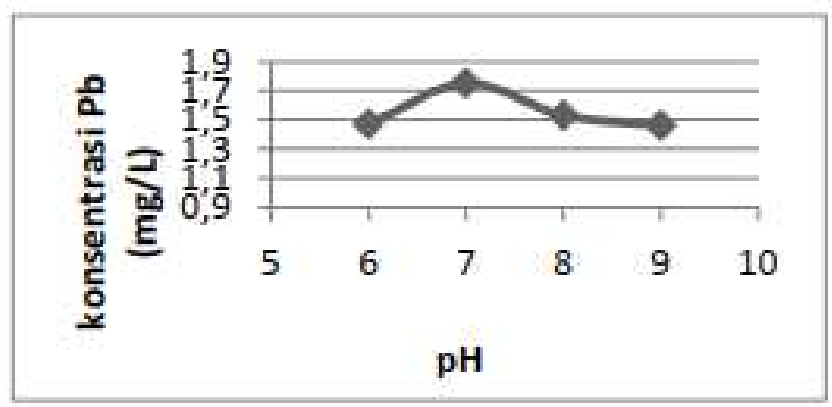

Gambar 2. Kurva Hubungan Konsentrasi Pb Terhadap pH

Berdasarkan kurva pada Gambar 2 terlihat bahwa konsentrasi $\mathrm{Pb}$ yang teradsorpsi pada $\mathrm{pH} 6$ adalah $1,47 \mathrm{mg} / \mathrm{L}$, sedangkan pada $\mathrm{pH} 7$ konsentrasi $\mathrm{Pb}$ yang teradsorp meningkat hingga $1,75 \mathrm{mg} / \mathrm{L}$. Kemudian pada $\mathrm{pH} 8$ dan $\mathrm{pH} 9$ konsentrasi $\mathrm{Pb}$ menurun menjadi masing-masing 1,53 mg/L dan 1,46 $\mathrm{mg} / \mathrm{L}$.

Pada $\mathrm{pH}$ netral, penambahan koagulan akan menghasilkan muatan-muatan negatif yang saling tolak menolak dan akan ternetralisasi oleh ion-ion negatif dari koagulan, dan akan saling tarik menarik serta membentuk flok (Bao dkk. 2005). Menurut Pernitsky (2003) pada pH 7 koagulan PAC menghasilkan ion $\mathrm{Cl}^{-}$dan gugus $\mathrm{OH}^{-}$yang banyak sehingga logam timbal yang berikatan juga semakin banyak. Pada kondisi ini terjadi pembentukan flok yang maksimal. Berdasarkan hasil analisis, adsorpsi logam $\mathrm{Pb}$ oleh koagulan PAC terjadi secara optimum pada $\mathrm{pH}$ lindi sebesar 7 .

\section{Koagulasi menggunakan Polialuminium Klorida (PAC)}

Proses koagulasi dilakukan dengan cara sampel lindi dikondisikan pada $\mathrm{pH}$ optimum menggunakan larutan $\mathrm{NaOH}$ selanjutnya ditambahkan larutan PAC dengan variasi konsentrasi 500 $\mathrm{mg} / \mathrm{L}, 600 \mathrm{mg} / \mathrm{L}, 700 \mathrm{mg} / \mathrm{L}, 800 \mathrm{mg} / \mathrm{L}$ dan $1000 \mathrm{mg} / \mathrm{L}$, kemudian dilakukan pengadukan.

Hasil analisis koagulasi Pb menggunakan PAC dengan variasi konsentrasi PAC $500 \mathrm{mg} / \mathrm{L}, 600$ $\mathrm{mg} / \mathrm{L}, 700 \mathrm{mg} / \mathrm{L}, 800 \mathrm{mg} / \mathrm{L}$ dan $1000 \mathrm{mg} / \mathrm{L}$ menunjukan terjadinya peningkatan $\mathrm{Pb}$ yang diserap oleh 
PAC. Ketika koagulan PAC ditambahkan ke dalam lindi, PAC akan terdisosiasi menjadi muatan positif dan negatif sehingga dapat menarik dan mengggabungkan partikel di dalam lindi (Al-Kdasi dkk., 2004). Berkurangnya konsentrasi $\mathrm{Pb}$ di dalam lindi disebabkan karena ion $\mathrm{Cl}^{-}$dan gugus $\mathrm{OH}^{-}$ dalam PAC yang ditambahkan ke dalam sampel juga semakin banyak. Hal ini menyebabkan kedua ion ini mampu mengikat $\mathrm{Pb}$ yang ada dalam lindi. Semakin besar konsentrasi PAC semakin banyak sisi aktif yang akan mengikat $\mathrm{Pb}$ di dalam lindi. Gambar 3 memperlihatkan tentang hubungan konsentrasi $\mathrm{Pb}$ terhadap konsentrasi PAC.

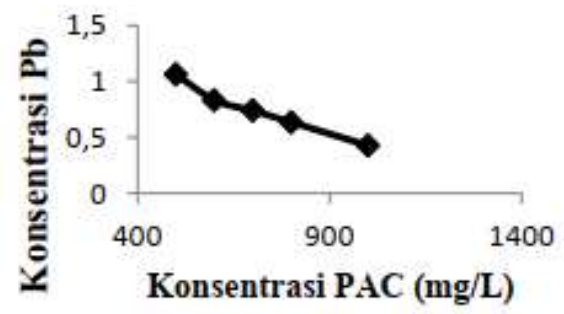

Gambar 3. Kurva Hubungan Konsentrasi Pb Terhadap Konsentrasi PAC

Berdasarkan hasil analisis (Gambar 3) maka disimpulkan bahwa semakin besar konsentrasi koagulan PAC maka penyerapan logam $\mathrm{Pb}$ semakin besar atau dengan kata lain semakin besar konsentrasi PAC maka konsentrasi logam $\mathrm{Pb}$ yang diserap oleh PAC semakin besar dan konsentrasi logam $\mathrm{Pb}$ dalam lindi menjadi semakin kecil. Persentasi efisiensi penyerapan $\mathrm{Pb}$ oleh PAC dalam lindi dicantumkan pada Gambar 4.

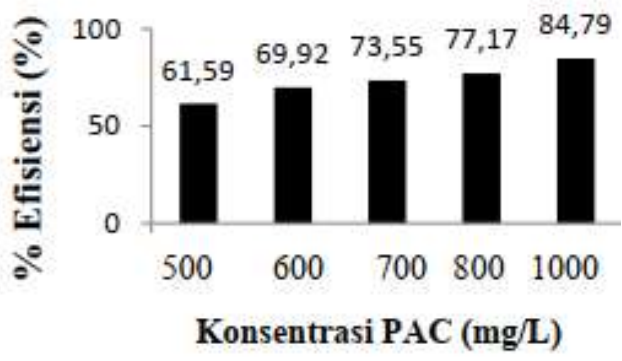

Gambar 4. Kurva \% Efisiensi Terhadap Konsentrasi PAC

Efektivitas PAC dapat ditentukan dari tingkat efisiensi penyerapan. Tingkat efisiensi penyerapan oleh PAC dihitung menggunakan rumus persen efisiensi dengan tujuan untuk mengetahui kemampuan koagulan PAC dalam menurunkan konsentrasi $\mathrm{Pb}$ dalam lindi. Data analisis konsentrasi PAC dengan konsentrasi 500, 600, 700, 800 dan $1000 \mathrm{mg} / \mathrm{L}$ dengan tingkat efisiensi penyerapan masing-masing sebesar $61,59 \% ; 69,92 \% ; 73,55 \% ; 77,17 \%$ dan $84,79 \%$ (Tabel 4.3 ). Semakin besar konsentrasi PAC maka semakin kecil konsetrasi $\mathrm{Pb}$ dalam lindi dan persen efisiensi semakin meningkat. Tingkat efisiensi penyerapan tertinggi pada konsentrasi PAC $1000 \mathrm{mg} / \mathrm{L}$ yaitu $84,79 \%$.

Tingkat efisiensi penyerapan $\mathrm{Pb}$ oleh PAC dengan variasi konsentrasi $500 \mathrm{mg} / \mathrm{L}-1000 \mathrm{mg} / \mathrm{L}$ menunjukkan peningkatan $\pm 3-8 \%$, maka dapat diperkirakan bahwa PAC masih efektif bekerja pada konsentrasi $>1000 \mathrm{mg} / \mathrm{L}$.

\section{KESIMPULAN}


Berdasarkan hasil penelitian dan pembahasan dapat disimpulkan sebagai berikut:

1. Kandungan konsentrasi logam $\mathrm{Pb}$ pada lindi di IPST Dusun Toisapu sebesar 2,67 mg/L.

2. Persentase koagulan $P A C$ dalam menurunkan logam $\mathrm{Pb}$ dalam Lindi dengan variasi konsentrasi PAC 500 mg/L; 600 mg/L; 700 mg/L; 800 mg/L; dan 1000 mg/L masing-masing sebesar 61,59\%; $69,92 \% ; 73,55 \% ; 77,17 \%$; dan $84,79 \%$.

\section{DAFTAR PUSTAKA}

Al-kdasi, A., Idris, A., Saed, K., dan Guan, C. 2004. Treatment of Textile Wastewater by Advanced Oxidation Process. Global Nest: The International Journal. Vol 6, No 3. Hal: 222-230.

Aminzadeh, B., Sarparastzadeh, H., Saeedi, M., dan Naeimpoor,F., 2007. Pretreatment Of unicipal Wastewater by Enhanced Chemical Coagulation. International Journal Environment Research. Vol 1, No 2. Hal : 104-113.

Bao, C., Yue, Q., Wang, B., dan Wang, S., 2005. Characterization and Coagulation of a Polyaluminum chloride (PAC) Coagulant with High $\mathrm{Al}_{13}$ Content. Journal of Enviromental Management. Vol 7, No 6. Hal: 143-147.

Day, R. A., dan Underwood, A. L., 2002. Analisis Kimia Kuantitatif, edisi keenam. (terjemahan: dr. Ir. lis Sopyan. M.Eng). Erlangga: Jakarta.

Davis, M. L., dan Cornwel, D. A., 1991. Introduction Environmental Engineering. Second Edition. New York: McGraw-Hill.

Gandhimati, R., Durai, N. J., Nidheesh, P. V., Ramesh, S. T., dan Kanmani, S., 2013. Use of Combined Coagulation-Adsorption Process as Pretreatment of Landfill Leachate. Iranian Journal of Environmental Health Science \& Engineering. Vol 10, No 24. Hal:1-7.

Gusnita, D., 2012. Pencemaran Logam Berat (Pb) di Udara dan Upaya Penghapusan Bensin Bertimbal. Berita Dirgantara. Vol 13, No 3. Hal: 95-101

Huliselan, E. K., dan Bijaksana, S., 2006. Magnetic Properties as Proxy Indicators of Heavy Metals in Leachate: A Case Study From Jelekong Solid Waste Disposal Site. International Conferences Mathematical and Natural Sciences. Physics of Complex System, Faculty of Mathematics and Natural Sciences, Bandung Institute of Technology. Hal: 819-822.

Kusmayadi, J. E., 1986. Identifikasi Unsur-unsur Pencemaran Kualitas Air Tanah Dangkal di Daerah Dago dan Sekitarnya. Laporan Penelitian. Teknik Geologi. Universitas Pajajaran Bandung.

Pernitsky, D. J., 2003. Coagulation. Associated engginer. Calgary Alberta. Hal:1-15

Sari, R.N., dan Afdal. 2017. Karakteristik Air Lindi (Leachate) di Tempat Pembuangan Akhir Sampah Air Dingin Kota Padang. Jurnal Fisika Unand.vol 6, No 1. Hal: 93-98.

Susanawati, D.L., Suharto, B., dan Kustamar. 2011. Penurunan Kandungan Logam Berat pada Lindi dengan Media Zeolit Menggunakan Metode Batch dan Metode Kontinyu. Jurnal Agrointek Vol 5, No 2. Hal:26-133.

Syahru, R., Alexander, T. S., dan Rahadi, B.W., 2013. Perbandingan Efektivitas Tepung Biji Kelor (Moringa oleifera Lamk), Poly Aluminium Chloride (PAC), dan Tawas sebagai Koagulan untuk Air Jernih. Jurnal Keteknikan Pertanian Tropis dan Biosistem.Vol 1, No 3. Hal: 186193.

Tchobanoglous, G. 1993. Integrated Solid Waste Management: Engineering Princiles and Management Issues. New York: McGraw-Hili,Inc.

Undang-Undang Republik Indonesia Nomor 18 tahun 2008 Tentang Sistem Pengolahan Sampah. Vouk, V., 1986. General Chemistry of Metals. In: Freiberg L. Nordberg G.F. and Vouk V.B (Eds). Handbook on the Toxicology of Metals. Elsevier: New York. 
Widyasari, N., Moelyaningrum, A.D., dan Pujiati, R.S., 2013. Analisis Potensi Cemaran Timbal (Pb) pada Tanah, air Lindi, Air Tanah (Sumur Monitring) di TPA Paku Sari Jember. Artikel IImiah Hasil Penelitian Mahasiswa. Universitas Jember. 